\title{
A hand to hold: communication during cataract surgery
}

\author{
Eye (2004) 18, 115-116. doi:10.1038/ \\ sj.eye. 6700569
}

Cataract surgery represents a remarkable modern success story. Ever since Jacques Daviel $^{1}$ in 1745 invented the 'modern' method of treating cataract by lens extraction (as opposed to couching), the procedure has improved with each significant advance in technique and technology. Today we are accustomed to routine day case phacoemulsification surgery often performed under 'minimal' local anaesthesia.

From the patient's point of view the first surgery must have been an absolute nightmare despite the motivation from the presence or threat of blindness. One of the reasons that Daviel made his incision at the inferior limbus was because the intense pain of the operation caused the patient's eye to roll upwards and in so doing allowed some judicious pressure on the lower lid to help the cataract escape.

The introduction in the second half of the 19th century of general anaesthesia for cataract surgery must have come as a blessed relief to both patient and surgeon. A little later (1884), but still relatively recently, cocaine was introduced and local anaesthesia for ophthalmology became rapidly accepted worldwide.

But local anaesthesia brings with it its own challenges and it is only recently that there has been wider acceptance of less invasive methods of ocular anaesthesia that are associated with a lower morbidity. Subtenon's or topical/intracameral anaesthesia is now considered to be safe and effective ${ }^{2}$ but both techniques require dexterity and confidence on the part of the surgeon and a patient who can cooperate fully, lie still, relatively flat, and tolerate their face being covered by a drape.

Nevertheless, cataract surgery under local anaesthesia may be a potent cause of worry, both preoperatively and during the procedure.
N Astbury

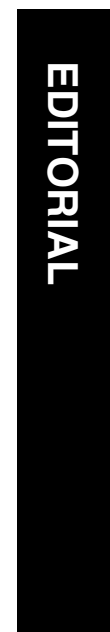

Anxiety can manifest itself in many ways, all of them potentially harmful to the patient or to the outcome of surgery. It activates the sympathetic nervous system and is characterised by a rise in catecholamine levels, heart rate, blood pressure, and increased glucocorticoid levels. At its worst it may place an ischaemic strain on the heart and cause hyperventilation or a panic attack. ${ }^{3,4}$ In addition, some patients become

claustrophobic under the drape and others may experience a variety of visual sensations that up to $15 \%$ find frightening. ${ }^{4}$

Various studies have been undertaken looking into factors that cause anxiety and into the emotional aspects of cataract surgery. ${ }^{5,6}$ Although one might imagine that the operation itself is the most stressful part, some patients may find the preassessment stage more anxietyprovoking than the operation day or the postoperative visit. ${ }^{5}$ Preoperative information and reassurance ${ }^{7}$ is helpful and indeed essential, although many patients prefer not to know details of the surgery itself. Groups of patients can gain support from each other or from talking to former cataract patients. ${ }^{8}$ Listening to music before and during surgery has been shown to be beneficial ${ }^{9,10}$ and in South Korea patients can enjoy a hand massage 5 minutes before surgery which has been shown to decrease both psychological and physiological anxiety levels. ${ }^{11}$

Despite these techniques, constant reassurance may be necessary in order to create a stress-free environment in which the patient can feel relaxed but still be able to communicate. One way of achieving this is by having a handholder or attendant who is often known to the patient beforehand and can perform a dual role, both monitoring the patient and providing tactile reassurance throughout the procedure. Over the past decade, the importance of the role of the hand-holder has increased as the amount of local anaesthetic administered has decreased. Hand-holders are most often nurses but may be befrienders ${ }^{12}$ or volunteers. In the USA,
Correspondence:

N Astbury

Consultant Opthalmologist Norfolk and Norwich University Hospital, Norwich UK

Tel: + 441603288374

E-mail: nick.astbury@

virgin.net
Fax: + 441603288261 
members of one hand-holder's club also qualify for a discount at the local optical store!

In this volume of Eye, Mokashi et al report on an electronic patient alert device (PAD) in lieu of the human equivalent and find that it is as effective a means of perioperative communication as holding a nurse's hand. Anxiolysis was measured using the proven six-item short form of the state scale of the Spielberger State-Trait Anxiety Inventory (STAI) ${ }^{13}$ and a self-evaluation questionnaire.

From personal experience of having been dropped and draped by my $\mathrm{SHO}$, prior to placing the speculum but holding back from doing the actual procedure, I can say that I found a hand to hold most comforting. When however my time comes for real, I may have no option but to hold the electronic device and have confidence in the surgeon!

With thanks to my SHO, Brian Ang, for checking the references and for preserving my cornea when cutting the drape.

\section{References}

1 Albert DM, Edwards DD. The History of Ophthalmology. Blackwell Science: Oxford, 1996.

2 The Royal College of Anaesthetists and the Royal College of Ophthalmologists. Local anaesthesia for intraocular surgery, The Royal College of Ophthalmologists. London 2001.
3 Moon JS, Cho KS. The effects of handholding on anxiety in cataract surgery patients under local anaesthesia. J Adv Nurs 2001; 35(3): 407-415.

4 Eong KG. Visual experience during cataract surgery. Ann Acad Med Singapore 2002; 31(5): 666-674.

5 Foggit PS. Anxiety in cataract surgery: pilot study. J Cataract Refract Surg 2001; 27(10): 1651-1655.

6 O'Malley Jr TP, Newmark TS, Rothman MI, Strassman HD. Emotional aspects of cataract surgery. Int J Psychiatry Med 1989; 19(1): 85-89.

7 Morrell G. Effect of structured preoperative teaching on anxiety levels of patients scheduled for cataract surgery. Insight 2001; 26(1): 4-9.

8 Parker P. The EyeCare Group: a volunteer support group for cataract patients. J Ophthalmic Nurs Technol 1990; 9(6): 240-242.

9 Bellan L, Gooi A, Rehsia S. The Misericordia Health Centre cataract comfort study. Can J Ophthalmol 2002; 37(3): 155-160.

10 Cruise CJ, Chung F, Yogendran S, Little D. Music increases satisfaction in elderly outpatients undergoing cataract surgery. Can J Anaesth 1997; 44(1): 43-48.

11 Kim MS, Cho KS, Woo H, Kim JH. Effects of hand massage on anxiety in cataract surgery using local anaesthesia. J Cataract Refract Surg 2001; 27(6): 884-890.

12 Befrienders help eye operation patients. West Suffolk Hospitals NHS Trust. News and Information, http:/ / www.wsufftrust.org.uk.

13 Marteau TM, Becker H. The development of a six-item short form of the state scale of the Spielberger State-Trait Anxiety Inventory (STAI). Br J Clin Psychol 1992; 31 (Part 3): 301-306. 